\title{
Presenting EMDR Therapy to Your Client
}

E. C. Hurley, DMin, PhD

\section{INTRODUCTION}

Purpose: This handout is for the therapist, not the client, as it emphasizes basic key points for the therapist to remember in establishing a positive treatment environment and therapeutic relationship with the client. These key points can help avoid early client dropout as well as confusion about treatment.

Recognizing that clients often struggle with the decision to seek treatment, creating a receptive clinical environment facilitates the client's acceptance of the treatment. Often vulnerability and feeling out of control are key issues, particularly with persons suffering with PTSD. Veterans who have been deployed in combat operations often express they never felt safe, and many never feel safe even after they return home. Asking about their security needs in your office, such as "What do you need to feel secure here?," lets the client know you are aware of their needs and clear up any concerns that could be roadblocks to treatment. Notice the word is "secure," avoiding the use of "safe" since many veterans believe there is no safe place anywhere.

Client: Explaining the connection between the client's need for change (what brought them to your office) and what you have to offer for resolving their needs is important early in the process. This means connecting the treatment goals with the treatment approach. The approach is reassuring, as it provides a sense of security while enhancing the client's motivation. Identifying the treatment goals and ensuring the client feels secure in your office allow them to continue with Phase 1, History-Taking, and the remaining phases of EMDR treatment. 


\section{OVERVIEW: CREATING THE SETTING IN YOUR OFFICE FOR EFFECTIVE TREATMENT OF YOUR CLIENT}

1. Client feels secure in your office. Client must feel safe/secure in your office to do effective clinical work.

2. Identify what brings the client in for treatment. This becomes the treatment goal(s).

3. Describe briefly how EMDR therapy can help the client achieve their treatment goals (connecting the treatment goals with the treatment plan using the AIP model). Note the past events that provide the emotional charge to the client's current present problem/symptoms.

4. The client's motivation to "get over" the presenting problem is the motivation of treatment.

5. Client provides a broad psychosocial history of what life has been like for.

6. Generate a resource list.

7. Generate a list of memories of disturbing events that continue to impact the client.

\section{CREATING A SECURE ENVIRONMENT}

Assess the client's perceived threat level in your office. How "on-guard" is the client? Can they relax enough to feel comfortable with you? A new client is already anxious, not knowing how the appointment will go. If it is an existing client, they will be introduced to a new approach so the novelty of the session can contribute to their anxiety. Effective treatment requires the client to feel secure enough in your office that they are is willing to be open to participate in the treatment process. Hypervigilant clients require more effort for the therapist in creating a secure treatment room allowing them to feel as calm as possible. Ask the client what they need to feel secure in your treatment environment. Note the client's ability to present their life experiences while selfregulating, even while remaining present and grounded in your office. Those who struggle with stabilization will require additional Phase 2 Preparation. Let the client know you will be working to ensure they are secure in every session.

\section{IDENTIFY THE TREATMENT GOALS}

What brings the client in for treatment? What do they wish to accomplish in coming to your office? Many want relief from being triggered 
by intrusive events in their life, that is, nightmares, flashbacks, being overreactive to sounds or smells, feeling of being cut off in situations. Recognize the client's reason for resolving their presenting problem(s) is also their motivation for effective treatment with EMDR therapy. Assess for secondary gains and the client's motivation for change. Remember, EMDR therapy will only do what the client wants done! If there is avoidance or other defense mechanisms, identify when/where they learned the pattern of avoidance as survival may need to be treated (as the target memory) first. Many therapists think they need to inundate the client with information about why the client needs EMDR therapy, but in reality the client wants relief and trusts you to know what you are doing. Most need brief information, such as EMDR therapy is recognized by leading professional organizations as being effective.

Present the professional recognition of EMDR therapy as an effective treatment for resolving the client's treatment goals. Explain EMDR therapy is recommended as being a treatment choice by the World Health Organization, the VA/DoD Clinical Practice Guidelines, and the Federal Government's Substance Abuse and Mental Health Administration (SAMHSA), among numerous other organizations.

As the therapist, remember EMDR therapy is a three-prong approach for identifying the presenting problem(s) of the client while using the AIP model, identifying those experiences the client wishes to resolve, and identifying what past events energize the present triggers.

In presenting EMDR therapy as a possible treatment, it can be helpful to remind your client, "EMDR therapy has been helpful for many dealing with similar issues. It might be helpful for you as well."

\section{ASSURE CLIENTS THAT YOU WANT TO LEARN WHAT LIFE HAS BEEN LIKE FOR THEM AS A MEANS OF UNDERSTANDING HOW TO BEST TREAT THEIR PRESENTING PROBLEM(S)}

The History-Taking phase is where you gather a broad psychosocial view of the client's life. Use your current history-taking approach. It can be helpful to review the attachment/bonding experiences beginning with childhood. The early childhood experiences develop patterns of relationship and problem-solving. Review these questions with clients.

What were their earliest memories of their caretaker responding to their needs?

Were they ignored or were their needs addressed?

How did these early life experiences impact how they manage life? 
Who could they count on? Who was there for them? Who believed in them?

Were there times they wished they were somewhere else and invented an imaginary world to cope with their dilemma?

Develop the resource list of positive life experiences-events that help clients feel good about themselves when they recall those achievements/accomplishments.

Note that everyone can identify issues that bother (upset) them when reminded. Develop a list of disturbing challenging memories of events which, when remembered, still bother them. Use the three techniques-direct questioning, float back, and affect scan-to search for past events, beginning with the presenting problem, and work backward.

From the list of challenging disturbing memories, select those that are connected to the presenting problems which bring the client in for treatment. These selected disturbing memories (connected to the presenting problems) become the treatment plan. Remember, EMDR therapy is a three-prong approach-treat the past events, the present triggers, and future template, unless modification is required.

\section{COMPLEX TRAUMA WITH HYPERVIGILANCE AND DISSOCIATIVE EXHIBITIONS}

1. Emphasize to the client that your first task is to work with them to relax enough to be calm in your office.

2. Introduce the client to various relaxation exercises, teaching them to self-regulate until they have some mastery of self-regulation.

Sometimes extended preparation is necessary with the client doing tapping and breathing exercises as they learn to self-regulate.

3. Ask the client to identify one distressing memory connected with their presenting problem in which they feel strong enough to work on the memory.

4. If the client still has difficulty reprocessing, consider flash technique, addressing the easiest target memory or contract with the client to do 10 to 15 minutes of reprocessing, then stop and review the experience and spend the necessary time for relaxation/containment in Phase 7 Closing. 